\title{
Microplastics in Landfills: A Comprehensive Review on Occurrence, Characteristics and Pathways to the Aquatic Environment
}

\author{
Kshitij Upadhyay $\dagger$ and Samir Bajpai \\ Department of Civil Engineering, National Institute of Technology, Raipur-492010, Chhattisgarh, India \\ †Corresponding author: Kshitij Upadhyay; kshitij.upadhyay111@gmail.com
}

\section{Nat. Env. \& Poll. Tech \\ Received: 12-03-2021 \\ Revised: 28-04-2021 \\ Accepted: 02-05-2021 \\ Key Words: \\ Microplastics \\ Landfill \\ Leachate \\ Degradation \\ Transfer pathways} Website: www.neptjournal.com

\begin{abstract}
Microplastics, a multi-dimensional environmental stressor group, capable of transboundary migration, are a threat to the global ecosystem. Transboundary migration of microplastics across all environmental matrices is known to originate from a multitude of sources and acts in conjugation with each other. This inter-dependence of sources calls for a detailed scientific analysis of all the sources that are in play. Waste management facilities have already been established as a significant contributor of microplastics to the aquatic and terrestrial environment. A systematic overview of the scientific literature reveals that the existing body of scientific knowledge is mainly focused on wastewater treatment facilities as a source/pathway of microplastics in the environment. Recently the focus shifted towards solid waste management facilities through landfills. Poor plastic waste management practices made discarded plastics the most dominant component of solid wastes. This review elucidates the occurrence and distribution of microplastics, characteristics of microplastics, including size, shapes, colors, and polymer types, in leachate and refuse of landfills. Furthermore, we discussed the transport mechanisms and pathways used by microplastic present in landfills to migrate to subsurface or groundwater and adjacent aquatic bodies. Last, based on the findings, we summarized the gaps in existing studies and suggested future perspectives to be focused on the future. The abundance of microplastics is attributed to the volume of plastic waste in landfills, management of leachate originating from landfills, application of leachate, and age of landfills. Microplastics abundance and characteristics vary in leachate and refuse. Smaller microplastics are predominant in leachate while larger microplastics are predominant in refuse. Landfills are capable of generating secondary microplastics from fragmentation and degradation. Further studies on microplastics in landfills are necessary to tackle this ever-growing menace.
\end{abstract}

\section{INTRODUCTION}

Mass production and increased consumption of plastics resulted in plastic accumulation in terrestrial and aquatic habitats (Colton \& Knapp 1974, Coe \& Rogers 2012). The plastic material, after its usefulness, ends up in the environment as waste or garbage (Gregory 1996, Moore et al. 2002, Derraik 2002). Plastic waste in the environment exists in different sizes range and classified as macroplastics, mesoplastics, and microplastics (Gregory \& Andrady 2003, Van Sebille et al. 2015). The term 'microplastic' was used by Thompson in 2004, to define smaller plastic pollutants present in the marine environment with emphasis been given to their size (Thompson et al. 2004). The size boundary used in defining microplastics was further refined by various authors (Andrady 2011, Arthur et al. 2008, Verschoor 2015).

The most popular and widely used definition of microplastics was proposed by United States National Oceanic and Atmospheric Administration (NOAA), defining 'microplastics' as any piece of plastic with upper size $<5 \mathrm{~mm}$, covering all types of plastic in the environment, regardless of the difference in chemical composition. Recently, a group of experts from this field, fixed the lower size limit of microplastics to $1 \mu \mathrm{m}$, to make results of future studies comparable and introduced a definition for submicron plastics (Size $<1$ $\mu \mathrm{m})$ known as nano plastics (Hartman et al. 2019).

The ever-growing body of scientific understanding from the studies demonstrates that microplastics are ubiquitous in the terrestrial environment and the terrestrial environment act as a "source and sink" for microplastics. A study reports that annual plastics released to land are estimated to be 4-23 times higher than that released to oceans (Geyer et al. 2017).

The major portion of plastic garbage after material/resource recovery and subsequent reuse, eventually ends up in landfills. It has been roughly estimated that $95 \%$ of MSW generated in the world ends up in landfills. The large portion of wastes in landfills is of plastic origin with a rough estimate to be $79 \%$, thereby suggesting landfills to be abundant with microplastics (Zhou et al. 2014). While waste management facilities such as wastewater treatment plants and landfills are presumed to be a potential source of microplastics, our 
understanding of the role of landfills as a source or sink of microplastics is limited (Ngo et al. 2019, Kazour et al. 2019, Cowger et al. 2019).

Landfill leachate, whether treated or otherwise, has been known to pollute environmental matrices with heavy metals and other toxic compounds, primarily in the soil and groundwater. Such contamination of groundwater results in a substantial risk to local groundwater resource users and the ecosystem. The presence of toxic plasticizers in leachate has been reported in many studies, which establish that landfills are a significant source of plastic-associated pollutants (Jonsson et al. 2003, Asakura et al. 2004, Baderna et al. 2011, Kalanatarifard \& Yang 2012, Wowkonowicz et al. 2013). Besides primary microplastics already present in the solid waste and landfills generates secondary microplastics due to the substantial amount of plastic waste buried in landfills and providing favorable environmental conditions for progressive and continuous degradation of macroplastics to microplastics (Ishigaki et al. 2004, Webb et al. 2013).

Thus, it is likely that landfills are also capable of storing, fragmenting, and releasing microplastics further in the environment, and may likely be the crucial link in better understanding the cyclic movement of microplastics in the environment. This paper aims to provide a review of the existing literature reporting microplastic pollution in landfills, focusing on their abundance and characteristics. Further, we examined whether landfills act as a sink, source of microplastics, or both and discussed transfer mechanisms of microplastics to the aquatic environment. Last, we discussed current gaps in knowledge regarding the understanding of microplastic pollution in landfills.

\section{RESULTS AND DISCUSSION}

\section{Microplastic Occurrence and Abundance in Landfills}

Results from 31 landfills that were examined in five studies portray that number of microplastics varies significantly with almost none to 25 particles per liter. The abundance of microplastics from each landfill site is mentioned in Table 1. The five studies considered under this review are geographically dispersed, spreading across Nordic countries of Europe to south Asian countries like China and Thailand, suggesting that microplastics are heterogeneously dispersed in landfills around the globe (Kilponen 2016, Praagh et al. 2018, He et al. 2019, Su et al. 2019, Puthcharoen \& Suchat 2019). This trend is in line with microplastic distribution in the aquatic and terrestrial environment around the globe, though microplastic abundances in landfills remain lower than in the aquatic ecosystem. Microplastics are found to be abundant in mostly all leachate samples.
This section also includes studies in which the reported quantity of microplastics in freshwater, sediment, and wastewater treatment plants are on par with the abundance of microplastics in landfills. Microplastic abundance and distribution in Flemish rivers of Belgium, River Seine of France, Lake Hovsgol of Mongolia, Great Lakes of USA, and various lakes of Switzerland are reported to be 17 particles. $L^{-1}, 0.03$ particles. $L^{-1}, 0.00012$ particles. $L^{-1}, 0.016$ particles. $L^{-1}$, and 20 particles. $L^{-1}$ respectively (Slootmaekers et al. 2019, Dris et al. 2015, Eriksen et al. 2013, Van Wezel et al. 2016, Faure et al. 2015).

A significant difference in microplastic abundance was observed among the analyzed landfill sites, with the highest abundance of microplastics recorded at landfill No. 2 of Shanghai, China (24.58 particles.L $\left.L^{-1}\right)$ and lowest around landfill site of Tali, Helniski (0.002 particles. $\left.L^{-1}\right)$. Furthermore, microplastic abundance varies from landfill to landfill within a country and other countries. Country-wise the maximum abundance was found at Álfsnes landfill (4.51 particles. $\left.\mathrm{L}^{-1}\right)$ in Iceland, Böler landfill (1.3 particles. $\left.\mathrm{L}^{-1}\right)$ in Norway, Hollola landfill (1.97 particles. $\left.\mathrm{L}^{-1}\right)$ in Finland, and Shanghai landfill No. 2 (24.58 particles. $\left.\mathrm{L}^{-1}\right)$ in China. This trend can be attributed to the difference in living standards, human activity, and type of industries, waste management practices, the quantity of plastic waste in MSW, and local laws and policies among countries. The nature and quantity of waste generated and handled by landfills are likely to be different, in turn influencing the abundance and characteristics of microplastics present in landfills. For example, the municipal solid waste of China has been reported to have less plastic content when compared with plastic content in municipal solid waste of Nordic countries (Yang et al. 2018). The other important aspect which affects the variation in microplastics abundance is the targeted microplastics size in the study. Variation in the mesh sizes or filter paper used during sampling and analysis influences the abundance of microplastic particles present in the samples.

Apart from leachate, refuse and dry waste from landfills was analyzed for the presence of microplastics in two studies. In the refuse sample obtained from Laogang landfill in Shanghai, China, the microplastic abundance was found to be in the range of 20-91 particle. $g^{-1}$. Similarly, in 12 landfills of Thailand, microplastic abundance in refuse was in the range of 0.6-2.2 particle. $\mathrm{g}^{-1}$. Microplastic abundance in landfill refuse is reportedly higher when compared with microplastic abundance in aquatic sediments, agricultural soil, and sewage sludge, again solidifying landfills as one of the major land-based sources of microplastics (Hu et al. 2015, Li et al. 2018, Liu et al. 2018).

Variation in leachate composition and concentration 
of pollutants when compared with refuse is attributed to the amount of water that infiltrates or percolates into the landfill and the environmental degradation and fragmentation processes occurring inside the landfill. Landfills are known to behave like an anaerobic reactor due to a favorable environment (sufficient moisture and lack of oxygen etc.), where a diverse range of microbial communities thrive. These microorganisms have the potential to bio-degrade plastic waste present in landfills depending on the environmental conditions of the landfill and the chemical nature of the polymer. Degradation of biodegradable plastics, through microbial activities in the landfill, results in the production of methane and biomass while degradation of other polymeric materials results in the production of microplastics. Hence the abundance of microplastics in landfills directly depends upon the volume of plastic waste present in the landfill, the volume of primary microplastics present in the landfill, and the degradation process occurring in the landfill (Ishigaki et al. 2004, Themelis \& Ulloa 2007)

\section{Characteristics and Nature of Microplastics in Landfill}

Characteristics of microplastics play a key role in the distribution and transference of microplastics in the environment. It is a common practice to characterize microplastics into different sizes; shapes, colors, and polymer types, etc. which aids in identifying the source, transfer pathway, fate, degradation status, potential to act as a vector for toxic chemicals and microbes, their interaction with organisms, and impact on the environment. The characteristics of microplastics from studies on landfills are summarized in Table 1.

\section{Size of Microplastics}

The size of the microplastics plays a crucial role in their interaction with the biotic component and long-term threat to the ecosystem. The lowest boundary of mesh size used during the sampling and analysis portion will fix the size of microplastics reported in the study. Continuous environmental degradation of macroplastics and microplastics keeps

Table 1: Abundance and characteristics of microplastics found in landfills.

\begin{tabular}{|c|c|c|c|c|c|}
\hline Location & $\begin{array}{l}\text { Abundance } \\
\text { (Particle/L) }\end{array}$ & Size Classification & Shape & $\begin{array}{l}\text { Microplastics polymer com- } \\
\text { position }(\%)\end{array}$ & Reference \\
\hline Álfsnes Iceland & 4.51 & \multirow{11}{*}{$\begin{array}{l}5,000-500 \mu \mathrm{m} \text { and } \\
500-50 \mu \mathrm{m}\end{array}$} & \multirow[t]{11}{*}{$\mathrm{NM}$} & \multirow{11}{*}{$\begin{array}{l}\text { PE }(41.46 \%), \text { PP }(4.27 \%), \\
\text { PVC }(2.07 \%), \text { PS }(12.26 \\
\%), \text { PET }(13.91 \%), \text { PUR } \\
(21.35 . \%), \text { PA }(0.55 \%), \\
\text { PMMA }(4.13 \%)\end{array}$} & \multirow[t]{11}{*}{ A } \\
\hline Anonymous $1 *$ Finland & 0.30 & & & & \\
\hline Anonymous $2 *$ Norway & 1.40 & & & & \\
\hline Böler Norway & 1.3 & & & & \\
\hline Fiflholt new cell Iceland & 0.20 & & & & \\
\hline Fiflholt old cell Iceland & - & & & & \\
\hline Gjerdrum Norway & 1 & & & & \\
\hline Hollola Finland & 1.97 & & & & \\
\hline Korvenmäki Finland & 1.10 & & & & \\
\hline Kujala Finland & 0 & & & & \\
\hline Topinoja Finland & 0.16 & & & & \\
\hline LF1 Shangha & CW: 3.58 EB: 18.38 & \multirow{6}{*}{$\begin{array}{l}1,000-5000 \mu \mathrm{m} \text { and } \\
1000-100 \mu \mathrm{m}\end{array}$} & \multirow{6}{*}{$\begin{array}{l}\text { lines }(14.81 \%) \text {, flakes } \\
(22.87 \%) \text { fragments } \\
(58.62 \%) \text {, pellets }(0.64 \\
\%) \text { and foams }(3.06 \%)\end{array}$} & \multirow{6}{*}{$\begin{array}{l}\text { PE }(34.94 \%), \text { PP }(34.94 \%), \\
\text { PVC }(0.32 \%), \text { PS }(4.99 \%), \\
\text { ABS }(0.32 \%), \text { PET }(5.96 \%), \\
\text { PUR }(1.45 \%), \text { EVA }(0.64 \%), \\
\text { PA }(0.64 \%), \text { PES }(2.74 \%), \\
\text { EP }(0.32 \%), \text { PF }(0.16 \%), \\
\text { PPC }(0.16), \text { PMMA } \\
(0.32 \%), \text { ALK }(4.35 \%), \\
\text { PMDS }(2.25 \%), \text { PTFE } \\
(5.48 \%) .\end{array}$} & \multirow[t]{6}{*}{ B } \\
\hline LF2 Shanghai & CW: 0.79 EB: 24.58 & & & & \\
\hline LF\# Shanghai & CW: $1.38 \mathrm{~EB}: 1.17$ & & & & \\
\hline LF4 Wuxi & CW: 0.96 EB: 0.96 & & & & \\
\hline LF5 Suzhou & CW: 0.42 EB: 2.96 & & & & \\
\hline LF6 Changzhou & CW: $2.21 \mathrm{~EB}: 3.58$ & & & & \\
\hline $\begin{array}{l}\text { Laogang, Shanghai, Chi- } \\
\text { na }\end{array}$ & 4 to 13 & $\begin{array}{l}<0.5 \mathrm{~mm} ; 0.5-1 \\
\mathrm{~mm} ; 1-5 \mathrm{~mm}\end{array}$ & $\begin{array}{l}\text { Leachate: fiber }(60 \%) \text {, } \\
\text { granules }(24.62 \%) \text {, frag- } \\
\text { ments }(15.38 \%), \text { Refuse: } \\
\text { fragments }(59.28 \%) \\
\text { granules }(18.57 \%) \text {, fibre } \\
(13.39 \%) \text { films }(7.86 \%) \\
\text { and rods }(0.36 \%)\end{array}$ & $\begin{array}{l}\text { Leachate: Cellophane } \\
(45.12 \%), \text { PE }(9.76 \%), P P \\
(8.54 \%) \text { and PS }(8.54 \%, \\
\text { refuse) } \\
\text { Refuse: PE, PEUR, PS, } \\
\text { EPM, and PP polymers ( } 60 \\
\%)\end{array}$ & $\mathrm{C}$ \\
\hline
\end{tabular}




\begin{tabular}{|c|c|c|c|c|c|}
\hline Location & $\begin{array}{l}\text { Abundance } \\
\text { (Particle/L) }\end{array}$ & Size Classification & Shape & $\begin{array}{l}\text { Microplastics polymer com- } \\
\text { position }(\%)\end{array}$ & Reference \\
\hline Tali, Helsinki & 0.002 and 0.017 . & $\begin{array}{l}<300 \mu \mathrm{m} ; 100 \mu \mathrm{m} \\
-300 \mu \mathrm{m} \text { and } 100 \mu \mathrm{m} \\
\text { to } 20 \mu \mathrm{m} .\end{array}$ & $\begin{array}{l}\text { Textile fibres : } 0.080 \text { to } \\
0.261 \text { fibres } / \mathrm{L} \text { and syn- } \\
\text { thetic particle : } 0.002 \text { and } \\
0.017 \text { particle } / \mathrm{L}\end{array}$ & NM & $\mathrm{D}$ \\
\hline \multicolumn{6}{|c|}{12 landfill of Thailand } \\
\hline & $\begin{array}{l}13.5-27.5 \text { Items/ } \\
\text { kg.dry weight }\end{array}$ & $330 \mu \mathrm{m}$ to $5000 \mu \mathrm{m}$ & $\begin{array}{l}\text { Grannules: } 32 \% \text { films } \\
27 \% \text {, } \\
\text { irregulars } 22 \% \text { and spheres } \\
1 \% \\
\text { leachates: granules } 47 \% \\
\text { films }(28 \%) \text {, } \\
\text { fibers }(17 \%) \text {, irregular } \\
(8 \%) \text { and spheres }(0 \%) \text {. }\end{array}$ & PS, PP, PET & $\mathrm{E}$ \\
\hline
\end{tabular}

References: A - Praagh et al. (2018); B - He et al. (2019); C - Su et al. (2019); D - Kilponen (2016); E - Puthcharoen \& Suchat (2019)

generating secondary microplastics, making exact estimation of microplastics based on size tough. Furthermore, smaller microplastics with a larger surface area are more prone to sorptive processes making a higher possibility of adsorption of toxic pollutants. Out of 5 studies, size distribution was mentioned in 3 studies, Detail of various size classifications used in the studies are summarized in Table 1.

Microplastics present in the leachate of 11 landfills of Nordic countries were classified in two size range- 5,000-500 $\mu \mathrm{m}$ and 500-50 $\mu \mathrm{m}$. Results concluded that when compared with raw or treated sewage, landfill leachate is likely to be a relatively small source of microplastic particles between 5000 and $50 \mu \mathrm{m}$. Microplastics present in leachate samples from 6 landfills of China were reported in 3 size classification. The highest percentage $(74.88 \%)$ of microplastics was found to be in the size range of 100-1000. Microplastics in leachate and refuse from Shanghai landfill were categorized into 3 classes, $<0.5 \mathrm{~mm}, 0.5-1 \mathrm{~mm}$, and $1-5 \mathrm{~mm}$. The size of microplastics ranged from 0.07 to $3.67 \mathrm{~mm}$ in leachate, and 0.23 to $4.97 \mathrm{~mm}$ for refuse samples. The average size of microplastics in refuse $(1.03 \mathrm{~mm})$ was larger than leachate $(0.83 \mathrm{~mm})$ suggesting large microplastic particle entraps in refuse while smaller microplastics particles migrate to the leachate. It can also be inferred that, due to continuous environmental degradation of the large microplastic particle, smaller secondary microplastics are being generated which migrates to the leachates. Microplastics in leachate sample collected near Talli, Helniski were classified into 3 size groups: $<300 \mu \mathrm{m} ; 100 \mu \mathrm{m}-300 \mu \mathrm{m}$, and $100 \mu \mathrm{m}$ to $20 \mu \mathrm{m}$.

Results of the five studies revealed that the abundance of microplastic varies with the size fraction of microplastics. The smaller microplastics remain abundant in leachate while larger microplastics are abundant in refuse. In the aquatic environment, smaller particles are reported to be dominant in the entire microplastics size range due to continuous deg- radation and fragmentation; results from the landfill studies also confirm this trend (Isobe et al. 2014, Zhang et al. 2017, Auta et al. 2017).

Problems associated with reporting size distribution and abundance of microplastics in microplastic research studies due to different sampling strategies and analytical methods being used by researchers, make comparative studies challenging. Standardization and harmonization of the microplastic analysis protocols and guidelines for reporting the size distribution of microplastics are much needed to use the size distribution data efficiently (Filella, 2015).

\section{Shape of Microplastics}

Microplastics in the environment appear in a wide diversity of shapes. Visual identification of microplastics through naked eyes and microscopes reveals morphological characteristics such as shape and color. Microplastic morphologies commonly described in research literature include spheres, beads, pellets, foam, fibers, fragments, films, and flakes. The shape of environmental microplastics depends upon the type of microplastics. Primary microplastics are intentionally made in that form, as the specific shape of primary microplastics serves a specific purpose, for example, microbeads in facial cleansers and face scrubs. In nature, degradation and fragmentation of microplastics occur, where a wide range of mechanical forces act on the surface of plastic which results in rugged and irregular-shaped secondary microplastics. Secondary microplastics with sharp edges illustrate a recent introduction into the environment while smooth edges are associated with a large residence time (Hidalgo-Ruz et al. 2012, Free et al. 2017, Paco et al. 2014, Weinstein et al. 2016, Upadhyay \& Bajpai 2021).

Out of 5 studies, only 3 studies report the shape of microplastics. Microplastics in 12 leachate samples from 6 landfills were categorized into 5 groups: lines, flakes, fragments, 
pellets, and foams. Fragments and flakes were found in all samples. Pellets and foam were found only in the landfills of Shanghai. The majority of the microplastics found were irregular in shape and had rough edges suggesting that secondary microplastics are the major source of microplastics in landfill leachate. Morphologically, microplastics from Leogang, Shanghai, China was categorized as fibers, granules, films, rods, and fragments in leachate and fibers, granules, and films in refuse. In leachate samples, fibers $(60 \%)$ were abundant while in soil samples, fragments $(59.28 \%)$ were abundant as mentioned in Table 1 .

Microplastics in leachate from a landfill in Talli, Helsinki, were analyzed for the presence of textile fiber and synthetic particles. Fibers were prevalent in all the samples. Microplastics in 12 soil samples and 10 leachates from 12 landfills of Thailand were categorized as fibers, films, spheres, granules, and irregular. In soil and leachate samples, granules (32\% \& $47 \%$ respectively) were the dominant type of microplastics.

The shape is crucial in determining the sources and types of microplastics. The shape also reveals the residence time of microplastic, meaning when the microplastics entered into the environment. Resins and pellets are reported to be dominant in the aquatic environment near industrial activities, suggesting the use of primary microplastic in industries while fragments and foams remain dominant near heavy marine aquatic traffic, tourist spots, and marine environment, suggesting secondary microplastics due to degradation. In domestic wastewater and wastewater treatment plants, beads found in personal care products and textile fibers from textile washing forms the majority of microplastics while fibers form the major component of microplastics deposited from the atmosphere (Napper et al. 2015, Dris et al. 2016, Hernandez et al. 2017)
The abundance of irregular shapes and rough edges of microplastics resulting from fragmentation and degradation of microplastics, and the volume of plastic waste buried in landfills implies a long-term process of generation, accumulation, and release of microplastics in the landfills. Earlier studies concluded that the abundance of the fragment in the aquatic environment is the result of environmental weathering and fragmentation of larger plastic products, or input of effluents from the wastewater treatment plants and industrial activities or derived from vessel activities (cargo, fishing, etc.). Furthermore, microplastics of smaller size having an irregular shape and rough surface provides active sorption sites which increases the sorptive potential of microplastics. This coupled with a higher residence time of microplastics in the environment (more residence times, increases the likelihood to), enhances the environmental risk of leachate discharged to the environment (Koelmans et al. 2016, Machado et al, 2018).

\section{Color of Microplastics}

Pigments and dyes are used by plastic manufacturing industries to produce colored macroplastics and microplastics. The consensus among microplastic pollution researchers remains in favor of reporting color classification of microplastics with the majority of microplastic studies reporting quantitative data on different colors of microplastic in the environment; still, none of the studies on landfill reports any information related to microplastic color. Microplastics have been reported in a range of colors, including red, orange, yellow, brown, tan, off-white, white, grey, blue, green, etc. Transparent microplastics originate from single-use plastic such as plastic bags and plastic plates or cups or from industries where transparent microplastics are used as feed material. Colored microplastics are mainly secondary microplastics

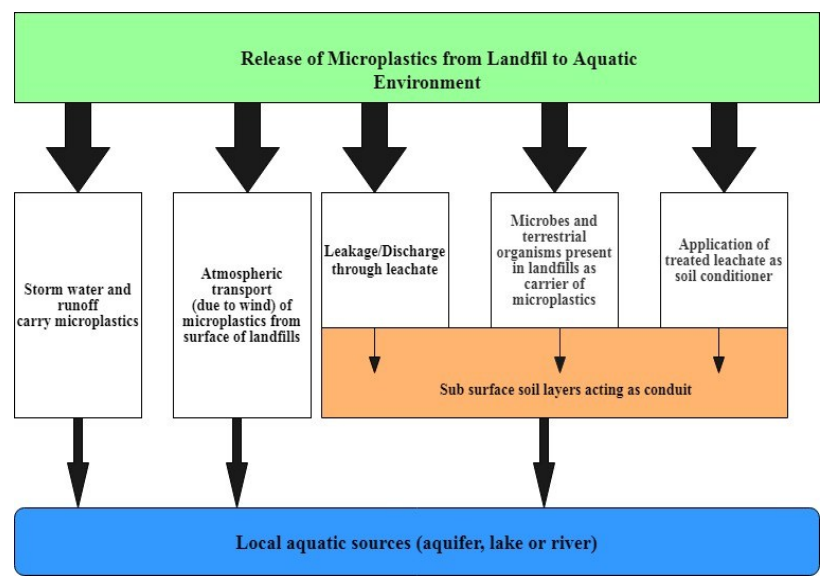

Fig.1: Potential pathways for microplastics migration and transference from landfills to aquatic environment. 
resulting from the fragmentation of colored macroplastics. However, the color of the plastic particle cannot easily be used to deduce the type or origin. Importantly, color information can be biased as brighter colors are spotted more easily during visual inspection.

\section{Polymer Type of Microplastics}

Analysis of the microplastic composition mainly in form of polymer types reveals pertinent useful information on an individual particle. The polymeric information alone can point towards sources and origin in most cases, but when supplemented with morphological information, will reveal the completed information (Digka et al. 2018).

726 microplastics present in 16 leachate samples (treated and untreated) from 11 landfills of the Nordic nation were identified to confirm the presence of 8 polymer types. PE (301 particles) was found to be abundant. 17 types of polymers were found in 621 microplastics particles from 12 leachate samples of 6 landfills in China. PE (217 particles) and PP (217 particles) dominated the entire polymer group (92). Microplastics present in leachate and refuse from landfills near Laogang, Shanghai, China were analyzed for polymer identification. For refuse samples, the highest abundance was represented by PE. In leachate samples, the highest abundance was represented by cellophane.

Polyethylene is the most dominating polymer type found in landfills. Cellophane, a typical semi-synthetic material, classified as microplastics, was abundant in landfills near Laogang, Shanghai, China. PE is also observed to be the most frequent polymer type found in other environmental matrices. In the aquatic environment, PE, PP, and PS microplastics are dominant. Similarly, PS and PE are the most detected microplastic polymer in wastewater samples (Van Sebille et al. 2015, Galgani et al. 2015, Ballent et al. 2016, Talvitie et al. 2017).

Polythene dominates the most produced polymer type in the world and has a wide range of applications such as packaging material and in personal care products. PS is extensively used in packaging and for manufacturing disposable items (coffee cups and food containers, eating utensils), while $\mathrm{PP}$ is used to make rigid plastic tools and furnishings, such as textile floor coverings, carpets, and fishing nets. Cellophane is often used as packing material for food items, batteries, and cigars (Vianello et al. 2013, 2019, Su et al. 2016, Kershaw \& Rochman 2016).

\section{Migration and Transport of Microplastics from Landfills to Aquatic Environment}

The fate of microplastics in landfills not only deals with microplastics buried in the landfill but also the secondary microplastics generated in landfills. Waste present in landfills, over time, gets decomposed and starts sweating, and generates a sufficient quantity of liquid waste known as 'leachate'. Landfill leachate can be defined as the liquid effluents generated from rainwater percolation or infiltration through a landfill, as well as, the moisture present in the waste and the degradation of waste (Mukherjee et al. 2015, Costa et al. 2018). The quantity of leachate generated depends upon the intensity and duration of rainfall, evapotranspiration, surface runoff, groundwater infiltration, and degree of compaction of waste in landfills.

Landfill facilities have a special arrangement for the collection of leachates which are eventually being disposed of in the environment, with or without treatment (Salem et al. 2018). Areas near landfills have a greater possibility of groundwater contamination because of the potential pollution source of leachate originating from the nearby site (Mor et al. 2006). The leachate pollutes large amounts of groundwater, rendering it unsuitable for use. Such contamination of groundwater resources poses a substantial risk to local resource users and the natural environment (Han et al. 2016). The plastic waste present in landfills is subjected to various environmental forces that facilitate their fragmentation or degradation and horizontal or vertical movement either due to groundwater underflow or infiltration. Overtime the leachate generated in the landfill starts accumulating at the bottom of the landfill and percolates through the soil and reaches the groundwater (El-Fadel et al. 1997, Islam \& Singhal 2004, Themelis \& Ulloa 2007, Bilgili et al. 2007).

Microplastic contamination of groundwater from landfill leachate is of paramount importance due to its association with chemicals and pathogens. Their eco-toxicological effect depends upon various factors such as volume and toxicity of microplastics present in leachate, permeability and nature of the geological strata which govern vertical and horizontal distribution, and direction of groundwater flow. Of these factors, groundwater flow is crucial as groundwater moves slowly and continuously through the pervious strata of soil. If a landfill contaminates groundwater with microplastics, a plume of contamination will occur and aquatic sources in that plume will be contaminated. The dry (long) and wet (intense) cycle leads to accelerated dispersion of leachate in the surrounding areas causing microplastic contamination of subsurface water.

The transport mechanism of microplastics from landfills is complex and remains unidentified, though few mechanisms have been conceptualized based on the transport and fate of microplastics in soil and terrestrial environment. Microplastics from landfills can transfer to groundwater and nearby water bodies using 5 distinct routes as shown in Fig. 1. 


\section{Stormwater or surface runoff carries microplastics} from landfills into aquatic systems: Stormwater runoff is an important pathway for the transport of microplastics from landfills to groundwater and aquatic bodies. Macroplastics and microplastics present near roads, on the ground surface, in open solid waste dumping sites and landfills, gets carried away with surface runoff which eventually ends up being part of groundwater or aquatic system. The presence of microplastics in surface runoffs has already been reported and modeling studies confirm that surface runoffs carry microplastics (including tire wear and road wear/dust particle) from terrestrial to the aquatic environment (Nizzetto et al. 2016, Siegfried et al. 2017, Vogelsang et al. 2019, Kole et al. 2017).

II. Atmospheric transport (due to wind) of microplastics from the surface of landfills to the aquatic environment: Microplastics are light in weight and their atmospheric transport has been highlighted as an important pathway that carries microplastics in the environment. Microplastics having low buoyancy, get carried away from the surface of the landfill by the wind and may deposit into aquatic bodies. Researchers have discovered that wind pushes and mixes the lightweight plastic particle down into the water (Rezaei et al. 2019). The wind can carry microplastics from the ground surface, open solid waste dump sites, and landfills and deposits them in environments farther from their original site, including the aquatic environment (et al. 2021).

III. Transference through leachate either by direct discharge or leakage from drainage: Leakage of leachate due to defects in landfill liners have been a matter of concerns for so long, Sufficient evidence is available which suggests that leakage through landfill liners would be a pathway for microplastics to enter into the adjacent environmental matrix (from subsurface soil to groundwater which eventually ends up in aquatic sources) (Foose et al. 2001). The immediate surface below landfill and landfill themselves are composed of porous soil medium containing pores of different sizes. These pores provide an opportunity for contaminants like microplastics to escape from the landfill. Recent studies discussed the vertical and horizontal distribution of microplastics in soil. Smaller microplastics easily move through soil pores while larger microplastic gets trapped. Similarly, in landfills, smaller microplastics migrate through the pores while larger microplastics get trapped in the pore. Trapped microplastics are under constant environmental degradation forces and with time, they break down into smaller microplastics, which then escape through the pores and reach aquifers via soil (Foose et al. 2001, Blasing \& Amelung 2018, Grayling et al. 2018, Yong et al. 1992, Brandon et al. 2016).

IV. Microbes and terrestrial organisms present in landfills as the carrier of microplastics: The most recent studies demonstrate that microbes and terrestrial organisms present in soil act as a carrier of microplastics. In laboratory conditions, two collembola species (i.e. Folsomia candida and Proisotoma minuta) carried and distributed microplastics. A study showed that mite (i.e. Hypoaspis aculeifermoved) can also move and disperse the commercial PVC microplastics. Similarly, earthworms were also observed to be the carrier of microplastics. Due to the abundance of microplastics in the terrestrial environment and terrestrial trophic transfer of microplastics, microplastics get ingested by terrestrial organisms and microbes. These organisms carry microplastics into the environment and release microplastics back to the environment through excretion. Microplastics can also get attached to the outer surface of organisms and migrate freely (Maaß et al. 2017, Zhu et al. 2018a, 2018b, Rillig et al. 2017, Huerta Lwanga et al. 2017a, 2017b)

V. Application of treated leachate as soil conditioner: Leachate, a toxic mix of chemicals, also contains minerals and nutrients (iron, nitrogen, phosphorus, and biomass from anaerobic digestion, etc.). Effluent from leachate treatment plants, after removal of toxic chemicals, contains a sufficient quantity of nutrients, which is used as a soil stabilizer and conditioner. Although technologies for the treatment of landfill leachate are mainly focused on the removal of toxic chemicals, they remain efficient in microplastic removal too. But the high volume of leachate effluent generated daily contains a huge amount of microplastics and when applied as a soil conditioner, will reintroduce microplastics back to the terrestrial environment from where they will migrate to aquatic sources (Nunes Júnior et al. 2017, Praagh et al. 2018).

Among transport mechanisms discussed above, leaking and disposal of leachate appear to be the dominant mechanism. Leachate being a highly concentrated chemical soup often undergoes treatment facilities to reduce its toxicity and volume. Despite the complex, efficient, and sophisticated treatment processes, just like wastewater effluent from wastewater treatment facilities, a substantial amount of microplastics remains present in treated leachate which eventually gets discharged either into the terrestrial environment or aquatic sources. Common leachate treatment processes include conditioning off leachate in equalization basins and subsequent physio-chemical and biological treatment units. The pathway for microplastic released from landfills to the environment will depend upon the discharge procedures adopted for treated leachate. Furthermore, the presence of microplastics from closed landfills of China highlights the importance of considering closed landfills as a source of microplastic pollution as degradation and fragmentation of microplastics is a continuous process.

The age of landfills is also an important fact to consider while addressing microplastic pollution in landfills. Landfill 
age is considered to be a determinant factor controlling the leachate composition because physio-chemical and biological properties change as the landfill tends to stabilize. The abundance and characteristics of microplastics in refuse have been reported to vary with different landfill ages. Due to increased plastic consumption in the last 3 decades, young landfills are abundant with microplastics while older landfill shows the presence of secondary microplastics resulting from environmental degradation (Kjeldsen et al. 2002, Kulikowska \& Klimiuk 2008, Su et al. 2019)

Apart from the aforementioned active traditional pathways, few passive transport pathways are available for microplastics to use. Landfill mining (excavation, screening, and separation of valuable materials in landfills) is an important form of resource recovery being used in many countries. The application of landfill materials (having high organic content and low toxic substances) as soil conditioner has been studied in various literature and are now being practiced (Hogland et al. 2004, Krook et al. 2012, Quaghebur et al. 2013, Jones et al. 2013, Canopoli et al. 2018). Sufficient evidence is now available which confirms that wastewater sludge used as soil conditioner contributes to soil contamination by microplastics (Corradini et al. 2019, Edo et al. 2020). The soil application of landfill refuse may introduce microplastics to the soil, from where they can either migrate to groundwater, accumulate in soils, or be transported and redistributed by wind or carried by surface run-off to the aquatic environment (Zubris \& Richards 2005, Duis \& Coors 2016, Da Costa 2018).

Compared with the aquatic environment, landfills are also a complex and heterogeneous medium where many factors (heterogeneous plastic waste, environmental condition, physio-chemical and biological properties of leachate and refuse) influence the transport of microplastics. The meteorological forces directly influence the abundance, distribution, and migration of microplastics. In the post-monsoon season, due to precipitation, the volume of leachate generated and volume of surface runoff increases, similarly, high wind may plausibly carry more microplastics from landfill surface (Van Breukelen et al. 2004, Wijesekara et al. 2014). How do these factors in association with external transport mechanisms affect the transport and retention of microplastics in landfills remains unsolved which affects our understanding of the transport of microplastics from landfills to soil and the aquatic environment. Future studies (laboratory studies, field studies, column experiments, transport modeling, and in-situ imaging) are required, considering all transport mechanisms individually and simultaneously to fill the knowledge gap highlighted in the next section.

\section{Knowledge Gap}

In this section, we are highlighting several key gaps in understanding microplastic pollution in landfills based on the published literature.

All the studies considered engineered landfills for analysis except few landfills in Thailand. Open dumping of municipal solid waste is commonly practiced in developing countries. Due to a lack of infrastructure and resources, these dumpsites generate leachate which directly flows to the drains or migrates to the groundwater. A holistic approach encompassing engineered landfills and open dumps is required to increase our understanding.

- The physicochemical properties of leachate have not been reported in many studies which makes it difficult to assess the overall risk of leachate on the ecosystem.

- Several studies have theoretically conceptualized the transfer route of microplastics from landfills to aquatic bodies, yet scientific understanding of transport mechanisms remains unclear. It is of paramount importance to understand the transport processes of microplastics originating from landfills to the environment. The microplastic transport and distribution among various zones of landfills must be modeled to estimate the level of microplastic abundance and distribution that has happened and that is going to happen. Furthermore, these models will help propose preventive measures.

- The body of knowledge available on microplastics in landfills is based on studies conducted in developed countries. Developing countries rely mostly on landfills and open dumps to deal with solid wastes. Given the fact that microplastics are capable of long-term transportation and transboundary migration, it is therefore important to address the presence of microplastic in developing countries.

- Further studies should focus on the plastic biodegradation process and underlying mechanism in the landfill, such as the isolation of microorganisms capable of degrading polymer and rate of degradation in field condition and controlled laboratory stimulated condition to make the predictive estimation of microplastics likely to generate in near future.

- Future studies need to investigate the ecotoxicological impact of microplastics originating from landfills by studying their interaction with toxic chemicals and pathogens already present in the landfill.

- Toxicological studies on the interaction of chemicals in leachate with microplastics in a laboratory simulated landfill environment are required to understand the distribution characteristics of microplastic-associated chemicals and sorptive behavior in the environment. 


\section{CONCLUSION}

Despite profound efforts to limit the use of landfills, landfills remain the most popular method to handle solid wastes. A review of the available literature indicates that microplastics are abundant in both active and closed landfills. The abundance and characteristics of microplastics varied across different regions. Fibers and fragments are the most dominant microplastic shapes and polyethylene is the most dominant polymer type in landfill leachate. Comparison of results is not possible due to varying size classification used in the study to report the abundance of microplastics. None of the studies reports a color classification of microplastics. Degradation and fragmentation of microplastics seem to generate secondary microplastics in landfills. The migration of microplastics present in landfills to groundwater is a continuous process that does not stop even after the ceasing of landfill operations. Hence, it is very essential to keep assessing and monitoring the surroundings of decommissioned landfill sites.

Finally, only through collaborative efforts of legislation, public participation, multi-disciplinary research effort, and advancement in research and monitoring, the issue of microplastic pollution can be properly addressed.

\section{REFERENCES}

Andrady, A.L. 2011. Microplastics in the marine environment. Mar. Pollut. Bull., 62: 1596-1605.

Arthur, C., Baker, J. and Bamford, H. 2008. The occurrence, effects, and fate of microplastic marine debris. Proceedings of the International Research Workshop on Microplastic Marine Debris, September 9-11, 2008, University of Washington Tacoma, Washington, USA, pp. 9-11.

Asakura, H., Matsuto, T. and Tanaka, N. 2004. The behavior of endocrine-disrupting chemicals in leachate from MSW landfill sites in Japan. Waste Manage., 24: 613-622.

Auta, H.S., Emenike, C.U. and Fauziah, S.H. 2017. Distribution and importance of microplastics in the marine environment: A review of the sources, fate, effects, and potential solutions. Environ. Int., 102: 165-176.

Baderna, D., Maggioni, S., Boriani, E., Gemma, S., Molteni, M., Lombardo, A. and Benfenati, E. 2011. A combined approach to investigate the toxicity of an industrial landfill's leachate: Chemical analyses, risk assessment, and in vitro assays. Environ. Res., 111: 603-613.

Ballent, A., Corcoran, P.L., Madden, O., Helm, P.A. and Longstaffe, F.J. 2016. Sources and sinks of microplastics in Canadian Lake Ontario nearshore, tributary, and beach sediments. Mar. Pollut. Bull., 110(1): 383-395.

Bilgili, M.S., Demir, A. and Özkaya, B. 2007. Influence of leachate recirculation on an aerobic and anaerobic decomposition of solid wastes. J. Hazard. Mater., 143(1-2): 177-183.

Blasing, M. and Amelung, W. 2018. Plastics in soil: Analytical methods and possible sources. Sci. Total Environ., 612: 422-435.

Brandon, J., Goldstein, M. and Ohman, M.D. 2016. Long-term aging and degradation of microplastic particles: Comparing in situ oceanic and experimental weathering patterns. Mar. Pollut. Bull., 110: 299-308.

Bullard, J.E., Ockelford, A., O'Brien, P. and Neuman, C.M. 2021. Preferential transport of microplastics by the wind. Atmos. Environ., 245:118038.

Canopoli, L., Fidalgo, B., Coulon, F. and Wagland, S.T. 2018. Physico-chem- ical properties of excavated plastic from landfill mining and current recycling routes. Waste Manage., 76: 55-67.

Coe, J.M. and Rogers, K.L. 2012. Marine debris: Sources, Impacts, and Solutions. Springer Science \& Business Media, Berlin, Germany.

Colton, J.B., Knapp, F.D. and Burns, B.R. 1974. Plastic particles in surface waters of the North-Western Atlantic. Science, 185: 491-497.

Corradini, F., Meza, P., Eguiluz, R., Casado, F., Huerta-Lwanga, E. and Geissen, V. 2019. Evidence of microplastic accumulation in agricultural soils from sewage sludge disposal. Sci. Total Environ., 671: 411-420.

Costa, J., Paço, A., Santos, P.S.M., Duarte, A.C. and Rocha-Santos, T. 2018. Microplastics in soils: Assessment, analytics and risks. Environ. Chem 16, 18-30.

Cowger, W., Gray, A.B., Eriksen, M., Moore, C. and Thiel, M. 2019. Evaluating wastewater effluent as a source of microplastics in environmental samples. In Karapanagioti, H.K. and Kalavrouziotis, I.K. (eds.), Microplastics in Water and Wastewater, IWA Publishing, London, UK, pp. 109-131.

Da Costa, J.P. 2018. Micro-and nano plastics in the environment: research and policymaking. Curr. Opin. Environ. Sci. Health, 1: 12-16.

Derraik, J.G. 2002. The pollution of the marine environment by plastic debris: A review. Mar. Pollut. Bull., 44: 842-852.

Digka, N., Tsangaris, C., Kaberi, H., Adamopoulou, A., Zeri, C. 2018. Microplastic abundance and polymer types in a Mediterranean environment. Proceedings of the International Conference on Microplastic Pollution in the Mediterranean Sea, 15-18 September, Italy, Springer, Cham, pp. 17-24.

Dris, R., Gasperi, J., Rocher, V., Saad, M., Renault, N. and Tassin, B. 2015. Microplastic contamination in an urban area: A case study in Greater Paris. Environ. Chem., 12: 592-599.

Dris, R., Gasperi, J., Saad, M., Mirande, C. and Tassin, B. 2016. Synthetic fibers in atmospheric fallout: A source of microplastics in the environment? Mar. Pollut. Bull., 104: 290-293.

Duis, K. and Coors, A. 2016. Microplastics in the aquatic and terrestrial environment: Sources (with a specific focus on personal care products), fate and effects. Environ. Sci. Europe, 28: 2.

Edo, C., González-Pleiter, M., Leganés, F., Fernández-Piñas, F. and Rosal, R. 2020. The fate of microplastics in wastewater treatment plants and their environmental dispersion with effluent and sludge. Environ. Pollut., 259: 113837.

El-Fadel, M., Findikakis, A.N. and Leckie, J.O. 1997. Modeling leachate generation and transport in solid waste landfills. Environ. Technol., 18(7): 669-686.

Eriksen, M., Mason, S., Wilson, S., Box, C., Zellers, A., Edwards, W., Farley, H. and Amato, S. 2013. Microplastic pollution in the surface waters of the Laurentian Great Lakes. Mar. Pollut. Bull., 77: 177-182.

Faure, F., Demars, C., Wieser, O., Kunz, M. and De Alencastro, L.F. 2015. Plastic pollution in Swiss surface waters: Nature and concentrations, interaction with pollutants. Environ. Chem., 12: 582-591.

Filella, M. 2015. Questions of size and numbers in environmental research on microplastics: Methodological and conceptual aspects. Environ. Chem., 12: 527-538.

Foose, G.J., Benson, C.H. and Edil, T.B. 2001. Predicting leakage through composite landfill liners. Journal of Geotechnical and Geoenvironmental Engineering 127, 510-520.

Free, C.M., Jensen, O.P., Mason, S.A., Eriksen, M., Williamson, N.J. and Boldgiv, B. 2014. High levels of microplastic pollution in a large, remote, mountain lake. Marine Pollution Bulletin 85, 156-163.

Galgani, F., Hanke, G. and Maes, T. 2015. Global Distribution, Composition, and Abundance of Marine Litter. In Bergmann,M., Gutow, L. and Klages, M. (Eds.), Marine Anthropogenic Litter . Springer, Cham, pp. 29-56.

Geyer, R., Jambeck, J. and Law, K.L. 2017. Production, use, and, the fate of all plastics ever made. Sci. Adv., 3: 1207-1221.

Grayling, K.M., Young, S.D., Roberts, C.J., Heer, M.I., Shirley, I.M. and Sturrock, C.J. 2018. The application of X-ray micro Computed Tomog- 
raphy imaging for tracing particle movement in the soil. Geoderma, 321: 8-14.

Gregory, M.R. 1996. Plastic 'scrubbers' in hand cleansers: A further (and minor) source for marine pollution identified. Mar. Pollut. Bull., 32: 867-871.

Gregory, M.R. and Andrady, A.L. 2003. Plastics in the marine environment. Plastics Environ., 379: 389-390.

Han, Z., Ma, H., Shi, G., He, L., Wei, L. and Shi, Q. 2016. A review of groundwater contamination near municipal solid waste landfill sites in China. Sci. Total Environ., 569: 1255-1264.

Hartman, N.B., Hüffer, T., Thompson, R.C., Hassellöv, M., Verschoor, A., Daugaard, A.E., Rist, S., Karlsson, T., Brennholt, N., Cole, M. and Herrling, M.P. 2019. Are we speaking the same language? Recommendations for a definition and categorization framework for plastic debris. Environ. Sci. Technol. 2019, 53, 3, 1039-1047,

He, P., Chen, L., Shao, L., Zhang, H. and Lü, F. 2019. Municipal solid waste (MSW) landfill: A source of microplastics?-Evidence of microplastics in landfill leachate. Water Res., 159: 38-45.

Hernandez, E., Nowack, B. and Mitrano, D.M. 2017. Polyester textiles as a source of microplastics from households: A mechanistic study to understand microfiber release during washing. Environ. Sci. Technol., 51: 70367046

Hidalgo-Ruz, V., Gutow, L., Thompson, R.C. and Thiel, M. 2012. Microplastics in the marine environment: A review of the methods used for identification and quantification. Environmental Science \& Technology 46, 3060-3075.

Hogland, W., Marques, M. and Nimmermark, S. 2004. Landfill mining and waste characterization: A strategy for remediation of contaminated areas. J. Mater. Cycles Waste Manag., 6: 119-124.

Hu, L., Chernick, M., Hinton, D.E. and Shi, H. 2018. Microplastics in small water bodies and tadpoles from Yangtze river delta, China. Environ. Sci. Technol 52, 88858893.

Huerta Lwanga, E., Gertsen, H., Gooren, H., Peters, P., Salanki, T. and Ploeg, M. 2017a. Incorporation of microplastics from litter into burrows of Lumbricus terrestris. Environ. Pollut., 220: 523-531.

Huerta Lwanga, E., Mendoza Vega, J., Ku Quej, V., Angeles Chi, J., Cid, L. and Chi, C. 2017b. Field evidence for transfer of plastic debris along a terrestrial food chain. Sci. Rep., 7: 1-7.

Ishigaki, T., Sugano, W., Nakanishi, A., Tateda, M., Ike, M. and Fujita, M. 2004. The degradability of biodegradable plastics in aerobic and anaerobic waste landfill model reactors. Chemosphere, 54: 225-233.

Islam, J. and Singhal, N. 2004. A laboratory study of landfill-leachate transport in soils. Water Res., 38(8): 2035-2042.

Isobe, A., Kubo, K., Tamura, Y., Kako, S., Nakashima, E. and Fujii, N. 2014. Selective transport of microplastics and mesoplastics by drifting in coastal waters. Mar. Pollut. Bull., 89, 324-330.

Jones, P.T., Geysen, D., Tielemans, Y., Van Passel, S., Pontikes, Y., Blanpain, B., Quaghebeur, M. and Hoekstra, N. 2013. Enhanced Landfill Mining in view of multiple resource recovery: A critical review. J. Cleaner Prod., 55: 45-55.

Jonsson, S., Ejlertsson, J., Ledin, A., Mersiowsky, I. and Svensson, B.H. 2003. Mono-and diesters from o-phthalic acid in leachates from different European landfills. Water Res., 37: 609-617.

Kalanatarifard, A. and Yang, G.S. 2012. Identification of the municipal solid waste characteristics and potential of plastic recovery at Bakri Landfill, Muar, Malaysia. J. Sustain. Dev., 5: 11.

Kazour, M., Terki, S., Rabhi, K., Jemaa, S., Khalaf, G. and Amara, R. 2019. Sources of microplastics pollution in the marine environment: Importance of wastewater treatment plant and coastal landfill. Mar. Pollut. Bull., 146: 608-618.

Kershaw, P.J. and Rochman, C.M. 2015. Sources, fate, and effects of microplastics in the marine environment: Part 2 of a global assessment, in: Reports and Studies-IMO/FAO/Unesco-IOC/WMO/IAEA/ UN/UNEP Joint Group of Experts on the Scientific Aspects of Marine
Environmental Protection (GESAMP.

Kjeldsen, P., Barlaz, M.A., Rooker, A.P., Baun, A., Ledin, A. and Christensen, T.H., 2002. Present and long-term composition of MSW landfill leachate: A review. Crit. Rev. Environ. Sci. Technol 32, 297-336.

Koelmans, A.A., Bakir, A., Burton, G.A. and Janssen, C.R. 2016. Microplastic as a vector for chemicals in the aquatic environment: Critical review and model-supported reinterpretation of empirical studies. Environ. Sci. Technol., 50: 33153326.

Kole, P.J., Löhr, A.J., Van Belleghem, F.G. and Ragas, A.M. 2017. Wear and tear of tires: A stealthy source of microplastics in the environment. Int. J. Environ. Res. Public Health, 14(10): 1265.

Krook, J., Svensson, N. and Eklund, M. 2012. Landfill mining: A critical review of two decades of research. Waste Manage., 32: 513-520.

Kulikowska, D. and Klimiuk, E. 2008. The effect of landfill age on municipal leachate composition. Bioresour. Technol., 99: 5981-5985.

Li, J., Zhang, H., Zhang, K., Yang, R., Li, R.and Li, Y. 2018. Characterization, source, and retention of microplastic in sandy beaches and mangrove wetlands of the Qinzhou Bay, China. Mar. Pollut. Bull., 136: $401-406$.

Liu, M., Lu, S., Song, Y., Lei, L., Hu, J., Lv, W., Zhou, W., Cao, C., Shi, H., Yang, X. and He, D. 2018. Microplastic and mesoplastic pollution in farmland soils in suburbs of Shanghai, China. Environ. Pollut., 242: 855-862.

Maßß, S., Daphi, D., Lehmann, A. and Rillig, M.C. 2017. Transport of microplastics by two collembolan species. Environ. Pollut., 225: 456-459.

Machado, A.A.D.S., Kloas, W. and Zarf, C.S.H. 2018. Microplastics as an emerging threat to terrestrial ecosystems. Glob. Chang. Biol., 24: $1405-1416$

Moore, C.J., Moore, S.L., Weisberg, S.B., Lattin, G.L. and Zellers, A.F. 2002. A comparison of neustonic plastic and zooplankton abundance in southern California's coastal waters. Mar. Pollut. Bull., 44: 1035-1038.

Mor, S., Ravindra, K., Dahiya, R.P. and Chandra, A. 2006. Leachate characterization and assessment of groundwater pollution near a municipal solid waste landfill site. Environ. Monit. Assess., 118(1): 435-456.

Mukherjee, S., Mukhopadhyay, S., Hashim, M.A. and Sen Gupta, B. 2015. Contemporary environmental issues of landfill leachate: Assessment and remedies. Crit. Rev. Environ. Sci. Technol., 45: 472-590.

Napper, I.E., Bakir, A., Rowland, S.J. and Thompson, R.C. 2015. Characterization, quantity and sorptive properties of microplastics extracted from cosmetics. Mar. Pollut. Bull., 99: 178-185.

Ngo, P.L., Pramanik, B.K. and Shah, K. 2019. Pathway, classification, and removal efficiency of microplastics in wastewater treatment plants. Environ. Pollut., 255: 411-431.

Nizzetto, L., Bussi, G., Futter, M.N., Butterfield, D. and Whitehead, P.G. 2016. A theoretical assessment of microplastic transport in river catchments and their retention by soils and river sediments. Environ. Sci.: Process. Imp., 18(8):1050-1059.

Nunes Júnior, F.H., Gondim, F.A., Pereira, M.D.S., Braga, B.B., Pontes Filho, R.A. and Barbosa, F.E. 2016. Sanitary landfill leachate as a source of nutrients on the initial growth of sunflower plants. Rev. Bras. de Eng. Agricola e Ambient., 20: 746-750.

Paco, A., Duarte, K., Costa, J.P., Santos, P.S., Pereira, R., Pereira, M.E., Freitas, A.C., Duarte, A.C. and Rocha-Santos, T.A. 2017. Biodegradation of polyethylene microplastics by the marine fungus Zalerion maritimum. Sci. Total Environ., 586: 10-15.

Praagh, M.V., Hartman, C. and Brandmyr, E. 2018. Microplastics in Landfill Leachates in the Nordic Countries. Nordic Council of Ministers, Copenhagen, Denmark, pp. 1-53.

Puthcharoen, A. and Suchat, L. 2019. Determination of microplastics in soil and leachate from the Landfills. Thai Environ. Eng. J., 33: 39-46.

Quaghebeur, M., Laenen, B., Geysen, D., Nielsen, P., Pontikes, Y., Van Gerven, T. and Spooren, J. 2013. Characterization of landfilled materials: Screening of the enhanced landfill mining potential. J. Cleaner Prod., 55: 72-83. 
Rezaei, M., Riksen, M.J., Sirjani, E., Sameni, A. and Geissen, V. 2019. Wind erosion as a driver for transport of light density microplastics. Sci. Total Environ., 669: 273-281.

Rillig, M.C., Ziersch, L. and Hempel, S. 2017. Microplastic transport in soil by earthworms. Sci. Rep., 7: 1362.

Salem, Z., Hamouri, K., Djemaa, R. and Allia, K., 2008. Evaluation of landfill leachate pollution and treatment. Desalination, 220(1-3):108-114.

Siegfried, M., Koelmans, A.A., Besseling, E. and Kroeze, C. 2017. Export of microplastics from land to sea. A modelling approach. Water Res., 127: 249-257.

Slootmaekers, B., Carteny, C.C., Belpaire, C., Saverwyns, S., Fremout, W., Blust, R. and Bervoets, L. 2019. Microplastic contamination in gudgeons (Gobio gobio) from Flemish rivers (Belgium). Environ. Pollut., 244: 675-684.

Su, L., Xue, Y., Li, L., Yang, D., Kolandhasamy, P., Li, D. and Shi, H. 2016. Microplastics in Taihu lake. China. Environ. Pollut., 216: 711-719.

Su, Y., Zhang, Z., Wu, D., Zhan, L., Shi, H. and Xie, B. 2019. Occurrence of microplastics in landfill systems and their fate with landfill age. Water Research 164, 114968.

Talvitie, J., Mikola, A., Koistinen, A. and Setälä, O. 2017. Solutions to microplastic pollution-Removal of microplastics from wastewater effluent with advanced wastewater treatment technologies. Water Res., 123: 401-407.

Themelis, N.J. and Ulloa, P.A. 2007. Methane generation in landfills. Renew. Energy 32: 1243-1257.

Themelis, N.J. and Ulloa, P.A. 2007. Methane generation in landfills. Renew. Energy., 32(7): 1243-1257.

Thompson, R.C., Olsen, Y., Mitchell, R.P., Davis, A., Rowland, S.J., John, A.W. and Russell, A.E. 2004. Lost at sea: Where is all the plastic? Science, 304: 838 .

Upadhayay, K., Bajpai, S. 2021. Microplastics: Pollution of emerging concern- what do we know so far? - A review. Pollution Research, 140-2.

Van Breukelen, B.M., Griffioen, J., Röling, W.F. and Van Verseveld, H.W. 2004. Reactive transport modeling of biogeochemical processes and carbon isotope geochemistry inside a landfill leachate plume. J. Contam. Hydrol., 70(3-4): 249-269.

Van Sebille, E., Wilcox, C., Lebreton, L., Maximenko, N., Hardesty, B.D., Van Franeker, J.A. and Law, K.L. 2015. A global inventory of small floating plastic debris. Environmental Research Letters 10: 124006.

Van Wezel, A., Caris, I. and Kools, S.A. 2016. Release of primary microplastics from consumer products to wastewater in The Netherlands. Environ, Toxicol. Chem., 35(7): 1627-1631.

Verschoor, A.J. 2015. Towards a definition of microplastics: Considerations for the specification of physico-chemical properties. RIVM Letter
Report 2015-0116, National Institute for Public Health and the Environment, Bilthoven, The Netherlands

Vianello, A., Boldrin, A., Guerriero, P., Moschino, V., Rella, R., Sturaro, A. and Da Ros, L. 2013. Microplastic particles in sediments of Lagoon of Venice, Italy: First observations on occurrence, spatial patterns and identification. Estuar. Coast Shelf Sci., 130: 5461.

Vianello, A., Jensen, R.L., Liu, L. and Vollertsen, J. 2019. Simulating human exposure to indoor airborne microplastics using a Breathing Thermal Manikin. Sci. Rep., 9: 1-11.

Vogelsang, C., Lusher, A., Dadkhah, M.E., Sundvor, I., Umar, M., Ranneklev, S.B., Eidsvoll, D. and Meland, S. 2019. Microplastics in road dust-characteristics, pathways, and measures. NIVA-Report, Oslo, Norway

Webb, H.K., Arnott, J., Crawford, R.J. and Ivanova, E.P. 2013. Plastic degradation and its environmental implications with special reference to poly (ethylene terephthalate). Polymers, $5: 1-18$.

Weinstein, J.E., Crocker, B.K. and Gray, A.D. 2016. From macroplastic to microplastic: Degradation of high density polyethylene, polypropylene, and polystyrene in a salt marsh habitat. Environ. Toxicol. Chem., 35: $1632-1640$

Wijesekara, S.S.R.M.D.H.R., Mayakaduwa, S.S., Siriwardana, A.R., de Silva, N., Basnayake, B.F.A., Kawamoto, K. and Vithanage, M. 2014. Fate and transport of pollutants through a municipal solid waste landfill leachate in Sri Lanka. Environ. Earth Sci., 72(5): 1707-1719.

Wowkonowicz, P. and Baranski, A. 2013. Release of di (2-ethylhexyl) and dibutyl phthalates from municipal landfills in Poland. Przem. Chem., 92: 2345-2350.

Yang, N., Damgaard, A., Scheutz, C., Shao, L.M. and He, P.J. 2018. A comparison of chemical MSW compositional data between China and Denmark. J. Environ. Sci., 74, 110.

Yong, R.N., Mohamed, A.M.O. and Warkentin, B.P. 1992. Principles of contaminant transport in soils. Stud. Environ. Sci., 70: 57-74.

Zhou, C., Fang, W., Xu, W., Cao, A. and Wang, R. 2014. Characteristics and the recovery potential of plastic wastes obtained from landfill mining. J. Cleaner Prod., 80: 80-86.

Zhu, D., Bi, Q.F., Xiang, Q., Chen, Q.L., Christie, P. and Ke, X. 2018a. Trophic predator-prey relationships promote the transport of microplastics compared with the single Hypoaspis aculeifer and Folsomia candida. Environ. Pollut., 235: 150-154.

Zhu, D., Chen, Q.L., An, X.L., Yang, X.R., Christie, P. and Ke, X. 2018b. Exposure of soil collembolans to microplastics perturbs their gut microbiota and alters their isotopic composition. Soil Biol. Biochem., 116: 302-310.

Zubris, K.A.V. and Richards, B.K. 2005. Synthetic fibers as an indicator of land application of sludge. Environ. Pollut., 138: 201-211. 